\section{Perianal Crohn Disease after Treatment with Rituximab for Active Granulomatosis with Polyangiitis}

\section{To the Editor:}

Rituximab (RTX) in combination with glucocorticoids has been recommended for relapsing granulomatosis with polyangiitis (GPA) if the disease remains active after a course of cyclophosphamide (CYC) lasting 3-6 months ${ }^{1}$. We describe a case of perianal Crohn disease (CD) in a patient with GPA who had been treated with RTX.

A 24-year-old woman with GPA was diagnosed in 2006 with bilateral cavitating pulmonary lesions on computed tomography, pauciimmune glomerulonephritis with crescents and extraglomerular arteritis on renal biopsy, mononeuritis multiplex, and proteinase 3 (PR3)-antineutrophil cytoplasmic antibodies (ANCA) of $>100 \mathrm{U} / \mathrm{ml}$. Six pulses of CYC with methylprednisolone were administered in 2006, but the patient experienced pulmonary and uveal recurrence of her GPA 5 weeks later. She had 1 course of 2 infusions of RTX ( $1 \mathrm{~g}$ per infusion) in combination with CYC in November 2006 (total cumulative CYC dose 7.5 g). In 2008 she developed headaches secondary to GPA recurrence affecting the pituitary gland confirmed by transsphenoidal biopsy and resulting in adrenocorticotropic hormone deficiency and cranial diabetes insipidus. She received 1 further course of RTX infusion in June 2008 with a further relapse (recurrence of headaches) in November 2009. Because azathioprine (AZA), methotrexate, and mycophenolate mofetil had been ineffective maintenance therapy, she began 6-monthly RTX infusions for 2 years. She received single RTX infusions (1 g each) in November 2009, August 2010, January 2011, and July 2011.

In April 2013 she developed perineal ulceration with granulation tissue on biopsy. The perineal disease progressed over the next year and developed into marked perianal ulceration by April 2014. Biopsy of the perineal skin showed mixed inflammatory cell infiltrate and colonoscopy was macroscopically normal. Microscopy revealed mild inflammatory changes with focal cryptitis, a preponderance of eosinophils not typical for inflammatory bowel disease (IBD), and crypt abscess formation. Magnetic resonance imaging (MRI) of the pelvis showed acute inflammation only. It was thought that the perianal ulceration was because of a recurrence of GPA and a further course of RTX was given in May 2014 (total cumulative RTX dose $10.8 \mathrm{~g}$ ). The patient was readmitted in September 2014 with worsening perianal pain, ulceration, and discharge (Figure 1). The perianal skin showed evidence of fissures and progressive ulceration. Repeat MRI pelvis revealed extensive fistulating disease with a marked rectovaginal fistula, and perianal skin biopsies showed granulomata, consistent with CD. Repeat colonoscopy and colonic biopsies were normal. Swabs grew perineal skin commensals and tuberculosis and herpes simplex virus swabs were negative. The patient is currently receiving treatment with AZA and infliximab for her $\mathrm{CD}$ with good effect (complete resolution of the 3 fistula).

ANCA are common in both GPA and IBD, and cytoplasmic-staining ANCA reacting with PR3 is predominantly found in GPA, but may be found in $\mathrm{CD}^{2}$. GPA can present similarly to $\mathrm{CD}$ and $\mathrm{CD}$ can mimic GPA, but it is thought that the presence of both conditions is exceptionally rare, with 1 case report series identifying only 13 patients over 20 years $^{2}$.

RTX is a chimeric anti-CD20 monoclonal antibody that targets B cell lymphocytes. Both $\mathrm{B}$ and $\mathrm{T}$ cells have been implicated in the pathogenesis of $\mathrm{GPA}^{3,4}$ and IBD. It has been suggested that B cells may not have a proinflammatory role in IBD and may have a protective effect, reducing inflammation by producing the antiinflammatory cytokine IL- $10^{5}$. There are only a few reports in the literature of induction or exacerbation of IBD by RTX.

A report of a 58-year-old man who underwent RTX salvage therapy for severe ulcerative colitis (UC) resulted in greatly depleted local and systemic $\mathrm{CD} 20+\mathrm{B}$ cells, but the patient experienced a severe exacerbation of $\mathrm{UC}^{5}$. Two similar reports describe a 62-year-old woman with disseminated B cell lymphoma and a 67-year-old man with follicular lymphoma who both developed fulminant colitis after RTX therapy ${ }^{6,7}$. Both patients required surgery after not responding to medical therapy. Other reports describe UC

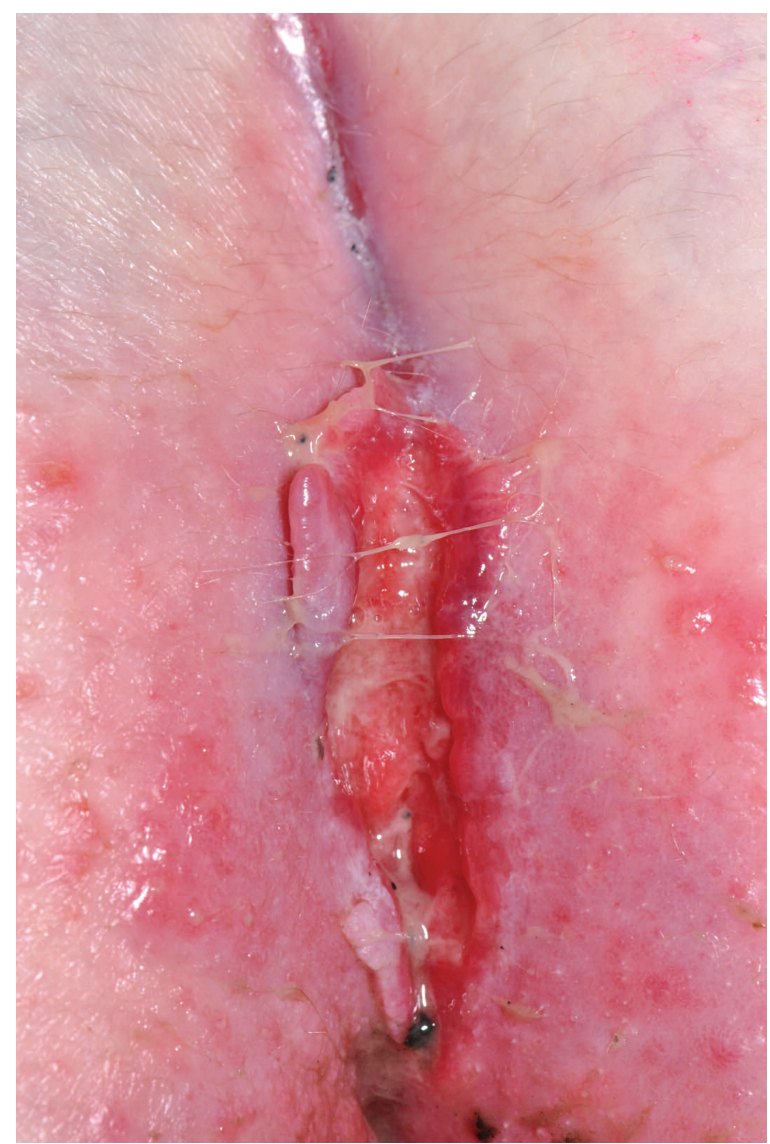

Figure 1. Perineal ulceration.

in a 4-year-old boy after receiving RTX for nephrotic syndrome, which responded to corticosteroids ${ }^{8}$, and a 45 -year-old woman with Grave disease with new-onset UC and arthritis following $\mathrm{RTX}^{9}$

Conversely, RTX was not associated with worsening of UC in a double-blinded randomized controlled trial consisting of 24 patients with moderately active $\mathrm{UC}^{10}$

Colitis may be associated with hypogammaglobulinemia. This has been reported with cytomegalovirus colitis in a patient with rheumatoid arthritis ${ }^{11}$, and in association with common variable immunodeficiency ${ }^{12}$. Our patient had normal immunoglobulin (Ig) levels prior to RTX therapy. However, thereafter the patient had low $\operatorname{IgM}(0.11-0.22 \mathrm{~g} / \mathrm{l})$ following the first RTX course until April 2012, when the level normalized. Low IgG (5.6 g/l) was noted after the last RTX course in May 2014.

RTX is effective in relapsing, refractory GPA. As shown in our case, RTX could induce or exacerbate IBD. Our patient had a normal colonoscopy with mild inflammatory changes on biopsy and perianal granulomata.

DAVID FRASER, MBCHB, Rheumatology Department, Western General Hospital; STEPHEN BOYLE, MRCP, Rheumatology Department, Western General Hospital; NICOLE AMFT, FRCP, Rheumatology Department, Western General Hospital, Edinburgh, UK. Address correspondence to Dr. S. Boyle, Rheumatology Department, Western General Hospital, Crewe Road South, Edinburgh EH4 2XU, UK. E-mail: boyledoc@yahoo.co.uk

\section{REFERENCES}

1. National Institute for Health and Care Excellence. Rituximab in combination with glucocorticoids for treating anti-neutrophil cytoplasmic antibody-associated vasculitis. [Internet. Accessed September 27, 2016.] Available from: www.nice.org.uk/guidance/ta308?unlid=829516852016127114125 
2. Vaszar LT, Orzechowski NM, Specks U, Ytterberg SR, Loftus EV Jr, Mark EJ, et al. Coexistent pulmonary granulomatosis with polyangiitis (Wegener granulomatosis) and Crohn disease. Am J Surg Pathol 2014;38:354-9.

3. Hinze CH, Colbert RA. B-cell depletion in Wegener's granulomatosis. Clinic Rev Allerg Immunol 2008;34:372-9.

4. Savage CO, Harper L, Holland M. New findings in pathogenesis of antineutrophil cytoplasm antibody-associated vasculitis. Curr Opin Rheumatol 2002;14:15-22.

5. Goetz M, Atreya R, Ghalibafian M, Galle PR, Neurath MF. Exacerbation of ulcerative colitis after rituximab salvage therapy. Inflamm Bowel Dis 2007;13:1365-8.

6. Lipka S, Katz S, Zia R, Crawford J, Ramek J. Fulminant colitis following rituximab therapy for disseminated $\mathrm{B}$ cell marginal lymphoma: P-16. Inflamm Bowel Dis 2012;18:S19-20.

7. Blombery P, Prince HM, Levinson M, Pianko S, Maxwell E, Bhathal P. Rituximab-induced immunodysregulatory ileocolitis in a patient with follicular lymphoma. J Clin Oncol 2011;29:e110-2.
8. Ardelean DS, Gonska T, Wires S, Cutz E, Griffiths A, Harvey E, et al. Severe ulcerative colitis after rituximab therapy. Pediatrics 2010;126:e243-6.

9. E1 Fassi D, Nielsen CH, Kjeldsen J, Clemmensen O, Hegedüs L. Ulcerative colitis following B lymphocyte depletion with rituximab in a patient with Graves' disease. Gut 2008;57:714-5.

10. Leiper K, Martin K, Ellis A, Subramanian S, Watson AJ, Christmas $\mathrm{SE}$, et al. Randomised placebo-controlled trial of rituximab (anti-CD20) in active ulcerative colitis. Gut 2011;60:1520-6.

11. Vallet H, Houitte R, Azria A, Mariette X. Cytomegalovirus colitis and hypo-IgG after rituximab therapy for rheumatoid arthritis. J Rheumatol 2011;38:965-6.

12. Borba de Arruda SM, do Rego Silva AM, Cezário de Barros KS, Cunha AM. Ulcerative colitis and common variable immunodeficiency: case report. Inflamm Bowel Dis 2009; $15: 478-81$.

J Rheumatol 2016;43:12; doi:10.3899/jrheum.160456 